ELSEVIER

\title{
Guidelines for Venous Thromboembolism and Clinical Practice in Italy: A Nationwide Survey
}

\author{
Stefano de Franciscis, ${ }^{1}$ Giovanni Battista Agus, ${ }^{2}$ Roberto Bisacci, ${ }^{3}$ Giuseppe Botta, ${ }^{4}$ \\ Vincenzo Gasbarro, ${ }^{5}$ Maurizio Domanin, ${ }^{2}$ Carmelo Giuseppe Angelo Nobile, ${ }^{6}$ \\ and Raffaele Serra, ${ }^{1}$ Catanzaro, Milan, Perugia, Siena, and Ferrara, Italy
}

\begin{abstract}
Venous thromboembolism (VTE) is a common health problem for today's society, and considering the role that it plays in surgical patients (general surgery, gynecology, and orthopedics), new advances in our understanding of the procedures and trauma characteristics are relevant and necessary. The most important and recently published guidelines concerning this problem have been taken into consideration, leading to articulate investigations and data evaluation. This project has proposed a data-survey framework available as a questionnaire in order to investigate application of the guidelines for VTE throughout the national territory. Of the total 714 Italian centers, a random sample of 214 were contacted and asked to take part in this study; of these, 146 replied ( $20.4 \%$ of total and $68.2 \%$ of the sample): 48 departments of general surgery, 46 departments of gynecology, and 52 departments of orthopedics. About $70 \%$ of the centers has appropriate information about surgery as a risk factor for VTE. The answers have provided evidence of an adequate knowledge of the instrumental and laboratory diagnostic pathways, useful to confirm the diagnosis of TE $(80 \%)$. Data waiting compared with morbidity and mortality rates related to deep vein thrombosis and pulmonary embolism showed an increase of mortality associated with the diagnostic data timing of supply, with an exponential trend linked to the data acquisition delay. Both risk stratification and adequate application of prophylaxis together with treatment devices represent a real tool to control morbidity and mortality for VTE. Moreover, diagnostic data waiting significantly influences adequate prophylaxis. In Italy, only $40 \%$ of the centers are ready to provide diagnostic data within $12 \mathrm{hr}$.
\end{abstract}

\section{INTRODUCTION}

The clinical impact and incidence of venous thromboembolism (VTE) have led to a number of leading

\footnotetext{
${ }^{1}$ Department of General Surgery, ${ }^{6}$ Department of Hygiene, University Magna Graecia of Catanzaro, Catanzaro, Italy.

${ }^{2}$ Department of Vascular Surgery, University of Milan, Milan, Italy Italy

${ }^{3}$ Department of Vascular Surgery, University of Perugia, Perugia,

${ }^{4}$ Department of General Surgery, University of Siena, Siena, Italy.

${ }^{5}$ Department of General Surgery, University of Ferrara, Ferrara Italy.

Correspondence to: Stefano de Franciscis, Department of Vascular Surgery, University Magna Graecia of Catanzaro, Viale Europa 88100 Catanzaro, Italy,E-mail: defranci@unicz.it

Ann Vasc Surg 2008; 22: 319-327

DOI: 10.1016/j.avsg.2007.09.014

(C) Annals of Vascular Surgery Inc.

Published online: May 8, 2008
}

scientific societies requesting an accurate definition of specific guidelines. The guidelines formulated by the American Society for Chest Physicians (ASCP) ${ }^{1}$ are routinely used for the stratification of risk and definition of procedures for prophylaxis and treatment.

According to such guidelines, over three-fourths of pulmonary embolism (PE) events occur in medical patients. ${ }^{2}$ However, because of the variety of risk factors in these patients and their individual health problems (e.g., comorbidities, therapies), ${ }^{3}$ the guidelines formulated for these cases are scarcely applied. The type of procedure as well as trauma are crucial for VTE in surgical patients (general surgery, gynecology, and orthopedics). Therefore, predictive algorithms that should help to identify high-risk subjects (i.e., those who require intensive prophylaxis) have been defined. ${ }^{2,4}$ Appropriate use of the guidelines is thus an opportunity to decrease 
mortality and morbidity rates in this setting. ${ }^{2,5,6}$ We have considered that, in addition to appropriate knowledge of the issue, the availability of specific technical resources in each health-care structure may affect dramatically the way guidelines are applied. We have evaluated the level of knowledge of VTE guidelines as well as the quantitative and qualitative information about diagnosis, prophylaxis, and treatment of a large number of Italian health departments that normally cope with patients at high risk of developing deep vein thrombosis (DVT) and PE.

Although studies based on questionnaires are generally considered not very rigorous and somewhat approximate, the significant amount of data collected in this work could stimulate further studies and strategies to implement guidelines about VTE in surgical settings.

\section{MATERIALS AND METHODS}

Of the total 714 public and private health-care facilities identified by each Health Regional Government Office and web search results, a random sample of 214 were contacted and asked to take part in the study. The self-administered questionnaire was mailed to selected participants and particularly to physicians who headed the general surgery, gynecology, and orthopedics wards in the centers who were responsible for answering the questionnaire, with an accompanying cover letter providing details on the purpose of the study and a reply-paid, addressed envelope. To keep track of who responded and to identify those who required follow-up, each returned envelope was individually coded with an identification number. To encourage participation of those who did not respond to the initial mailed questionnaire, in order to increase the response rate, telephone calls and two additional complete mailings, with another copy of the questionnaire and of the envelope, were sent to nonrespondents.

The standard form involved a certain number of questions (Fig. 1). In order to achieve better reliability of the collected data and to verify the quality of the practical approach carried out in each center, a series of filter questions were employed, with emphasis on laboratory and instrumental diagnostic devices and facilities for treatment, together with questions related to general information (i.e., not exclusively related to VTE). Five university centers (local units) supervised the forwarding and data collection.

Validation of the questionnaire to reveal major difficulties and weaknesses was performed through

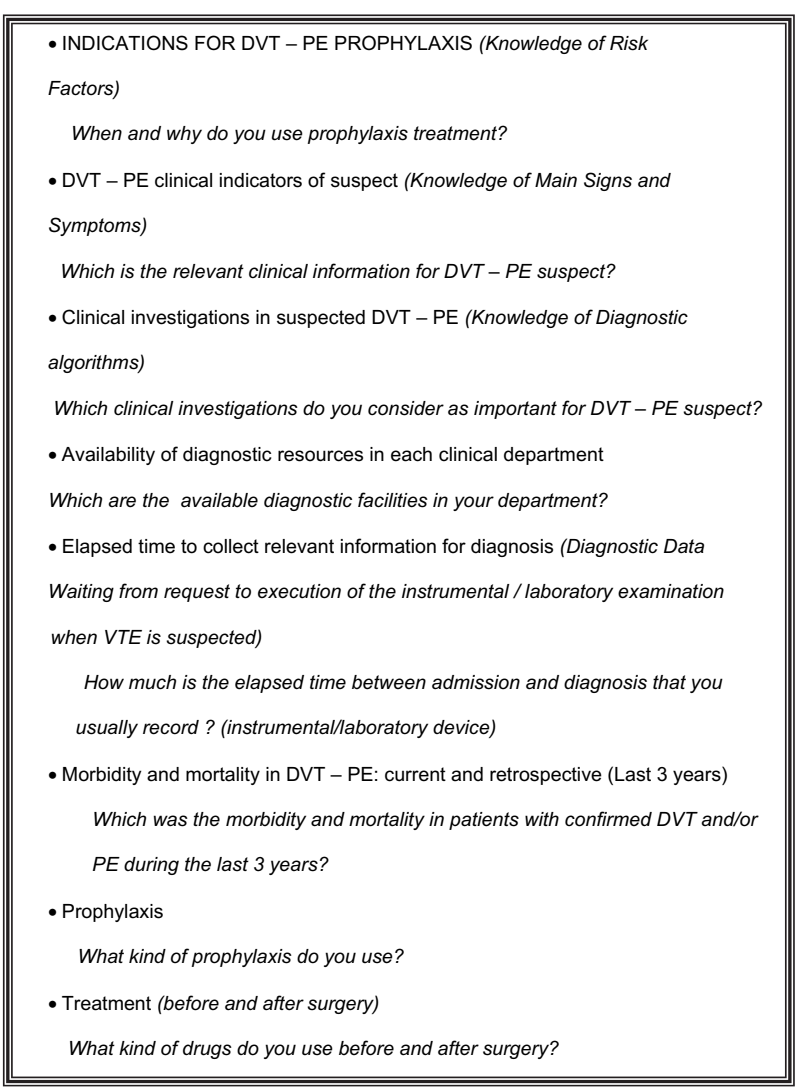

Fig. 1. The questionnaire.

a pilot study, surveying a convenience sample of 20 surgeons, gynecologists, and orthopedists; and on the basis of the results of the pretesting, modifications were made to improve the validity of responses.

\section{RESULTS}

Replies were received from 146 centers $(20.4 \%$ of total and $68.2 \%$ of the sample): 48 departments of general surgery, 46 departments of gynecology, and 52 departments of orthopedics.

Health-care centers were used by $12,391,240$ individuals ( $20.4 \%$ of the Italian population).

In order to make the statistical data analysis more uniform, stratification among centers in north $(25,600,000$ inhabitants), central $(10,900,000$ inhabitants), and south $(20,000,000$ inhabitants) Italy was chosen.

- Indications about DVT-PE prophylaxis (knowledge of the risk factors): About $70 \%$ of the centers possessed some appropriate information about surgery as a risk factor for VTE. Of this $70 \%$, only 
half reported knowing the other risk factors not related to surgery (Table I).

- Clinical indicators of suspect DVT-PE (knowledge of main signs and symptoms): About $80 \%$ of the centers reported pain and edema as signs of VTE; the same percentage of centers mentioned dyspnea and chest pain as symptoms of PE. Other signs and symptoms were underestimated (Table II).

- Procedural investigations in use for suspect DVT-PE (knowledge of the diagnostic algorithms): The diagnostic procedures to consider in case of suspected DVT are correctly followed by about $80 \%$ of the centers, while in case of suspected PE (similar to the choice between Computed Tomography Angiography [angio-TC] and Perfusional Scintigraphy [Perf-Scint]) the percentage rises to $90 \%$. Thus, the data suggest that more attention is paid to suspected PE rather than DVT (Table III).

- Availability of diagnostic resources in clinical departments: About $80 \%$ of the health care facilities employ diagnostic resources necessary to confirm DVT-PE. High-cost investigations (magnetic resonance angiography [angio-MR] 45-61\%, Scint radiolabeled Fibr 25\%) are less common than the essential diagnostic devices (90\%) (Table IV).

- Diagnostic data waiting: Only $40 \%$ of the centers receive confirmation of the clinical suspicion within $12 \mathrm{hr}$; in some centers more than $48 \mathrm{hr}$ is necessary in order to get this important information. Generally, $24 \mathrm{hr}$ is requested for confirmation (Table V). There is a delay from the request to the execution when VTE is presumed (the same for DVT and PE).

- Annual and triennial mortality for DVT-PE number of cases per 100,000 inhabitants): The recruited centers replied to specific questions that asked for data related to mortality about patients with a certain diagnosis or post-mortem diagnosis (Table VI). It is interesting to note that the total mortality for DVT, as indicated by some physicians who answered the form, is probably due to PE events not diagnosed in patients with DVT.

- Prophylaxis: About $90 \%$ of the centers employ low-molecular weight heparin (LMWH) or opiate analgesic (oral anticoagulant [OA]) for prophylaxis; physical devices are used in $40 \%$ of cases (Table VII). No association is evident between risk categories and type of prophylaxis employed.

\section{Medical Treatment before and after Surgery}

Data analyses have shown that $70 \%$ of centers involved in this study usually use LMWH before surgery and $80 \%$ after surgery (Table VIII). OA
Table I. Knowledge of the risk factors of TE

\begin{tabular}{lc}
\hline Risk factors & $\%$ \\
\hline Immobilization & 40.3 \\
Major surgical procedures & 73.0 \\
Traumas & 32.6 \\
Neoplasias & 34.6 \\
Previous TE & 40.3 \\
Trombophilia & 23.6 \\
Obesity & 32.6 \\
Age $>60$ years & 48.0 \\
Venous disease & 44.2 \\
Other & 31.7 \\
\hline
\end{tabular}

Table II. Knowledge of the main signs and symptoms of DVT and PE

\begin{tabular}{lc}
\hline Main signs and symptoms & $\%$ \\
\hline DVT & \\
Pain & 89.3 \\
Edema & 76.3 \\
Fever & 24.4 \\
Cutaneous alterations & 28.2 \\
Functional alterations & 20.6 \\
Homans maneuvre-positive & 19.8 \\
Venous reticula & 14.5 \\
Other & 26.7 \\
PE & \\
Dyspnea & 92.5 \\
Thoracic pain & 70.1 \\
Cough & 27.6 \\
Tachypnea & 50.7 \\
Anxiety & 19.4 \\
Hemoptysis & 26.8 \\
Sweating & 19.4 \\
Other & 46.2 \\
\hline
\end{tabular}

treatment is seldom used $(0 / 0.93 \%)$. This attitude is based on the need to choose drugs with the best risk/benefit (protection/bleeding) ratio in preventing VTE.

Data concerning diagnostic data waiting and morbidity/mortality were further analyzed through stratification of the information divided according to specific areas (north, center, and south) (Table IX). There was a sufficient distribution of laboratory and instrumental diagnostic resources combined with an incongruous distribution of data waiting: only $40 \%$ of the centers were able to supply diagnostic data within $12 \mathrm{hr}$.

Data waiting were compared with morbidity and mortality rates related to DVT-PE (Table X, Figs. 24). Comparison between data waiting and mortality showed an increase of mortality in some way associated to the diagnostic data timing of supply, with an 
Table III. Knowledge of the diagnostic algorithms

\begin{tabular}{ll}
\hline Kind of device & $\%$ \\
\hline Echo color Doppler & 85.8 \\
Echo Doppler & 71.7 \\
Doppler & 44.9 \\
Phlebography & 21.2 \\
Marked fibrinogen vein scintigraphy & 29.5 \\
D-dimer evaluation & 83.2 \\
Hemocoagulation evaluation & 81.6 \\
Homocysteine evaluation & 36.2 \\
Thoracic radiography & 91.0 \\
Pulmonary spiral CT & 69.7 \\
Perfusional scintigraphy & 69.5 \\
Ventilatory scintigraphy & 38.8 \\
D-dimer evaluation & 93.8 \\
Hemocoagulation evaluation & 91.0 \\
Lactate dehydrogenase evaluation & 83.9 \\
Creatine phosphokinase evaluation & 79.7 \\
Alanine aminotransferase evaluation & 71.1 \\
\hline
\end{tabular}

exponential trend linked to the data acquisition delay.

Some data about mortality for DVT have surfaced, but they are of uncertain meaning.

\section{Morbidity and Mortality by Type of Clinical Center (Number of Cases per 100,000 Inhabitants)}

Data related to mortality and morbidity of TE linked to the specialty of the clinical departments where patients are treated were taken into consideration. Considering the collected information, an incongruity between data related to morbidity and mortality has emerged from the replies (Table XI, Figs. 5 and 6). Regarding the questionnaire, all the centers were asked to reply accurately to the specific requested information but only in case of confirmed morbidity and mortality.

\section{DISCUSSION}

For the last 10 years, detailed and exact guidelines for diagnosis, prophylaxis, and therapy for VTE have been circulating within the scientific community, becoming the gold standard for up-to-date practice. There is no study available about the application of these guidelines for VTE across a national territory or results from evaluation of experienced practices.

We received replies from 146 public and private clinical centers $(68.20 \%$ of the transmitted questionnaires), serving 12,391,240 inhabitants. Data collected from five university research units, each
Table IV. Availability of diagnostic resources

\begin{tabular}{lc}
\hline Kind of device & $\%$ \\
\hline Radiography & 99.1 \\
CT & 95.6 \\
MR & 58.1 \\
Phlebography & 59.1 \\
Ultrasonography & 92.6 \\
Angio-CT & 70.5 \\
Angio-MR & 45.6 \\
Plethysmography & 22.6 \\
Perfusional scintigraphy & 46.8 \\
Ventilatory scintigraphy & 27.3 \\
Marked fibrinogen vein scintigraphy & 25.0 \\
aPTT evaluation & 99.1 \\
PT evaluation & 100 \\
INR evaluation & 98.2 \\
Fibrinogen evaluation & 99.1 \\
Factor XII & 57.4 \\
D-dimer evaluation & 88.3 \\
FDP evaluation & 87.3 \\
Protein C evaluation & 82.9 \\
Protein S evaluation & 70.6 \\
AT III evaluation & 95.5 \\
Homocysteine evaluation & 57.4 \\
\hline
\end{tabular}

CT, computed tomography; MR, magnetic resonance; aPTT, activated partial thromboplastin time; PT, partial thromboplastin; INR, international normalized ratio; FDP, fibrinogen degradation product; AT III, antithrombin III; Angio TC, computed tomography angiography; Angio RM, magnetic resonance angiography.

of them responsible for some regions, were redistributed in classical divisions of the national territory (north, center, south). The distribution of centers in defined areas compared to the local population represents a valid sampling for statistical analysis (48 departments of general surgery, 46 departments of gynecology, 52 departments of orthopedics).

Our response rate was $68.2 \%$, and the survey was nationwide. This rate is consistent with other mailed physician surveys, in which the typical response is approximately $50 \%{ }^{7,8}$ Selection bias is always a concern and may limit the generalizability of the findings, and this may mean that those who did respond tended to support guidelines and were more likely to be more knowledgeable. Moreover, actual compliance with guidelines is probably lower among nonrespondents, while respondents may tend to overestimate the extent to which they comply in practice. We examined the impact of nonresponding physicians. The best approach suggested to understand the role of nonresponse bias is to use variables known for a sufficiently large and representative sample of nonresponders and to compare them with those of responders. ${ }^{9}$ We were able to compare baseline demographic and practice variables of 
Table V. Diagnostic data waiting

\begin{tabular}{lrcc}
\hline \multirow{2}{*}{ Kind of device } & \multicolumn{1}{c}{$<$ (2 } & $>12<48$ & $<48$ \\
& hr $(\%)$ & hr $(\%)$ & hr $(\%)$ \\
\hline Radiography & 61.6 & 31.5 & 6.8 \\
CT & 44.0 & 29.3 & 26.6 \\
MR & 42.0 & 8.0 & 50.0 \\
Phlebography & 2.6 & 74.4 & 23.1 \\
Ultrasonography & 52.0 & 28.1 & 19.8 \\
Angio-CT & 26.8 & 36.6 & 35.6 \\
Angio-MR & 33.3 & 8.3 & 46.7 \\
Plethysmography & 40.0 & 46.7 & 13.3 \\
Perfusional scintigraphy & 11.1 & 66.7 & 22.2 \\
Ventilatory scintigraphy & 18.2 & 18.2 & 63.6 \\
Marked fibrinogen vein & 33.3 & 50.0 & 16.7 \\
$\quad$ scintigraphy & & & \\
aPTT evaluation & 46.7 & 25.3 & 28.1 \\
PT evaluation & 46.7 & 25.3 & 28.1 \\
INR evaluation & 46.7 & 25.3 & 28.1 \\
Fibrinogen evaluation & 45.9 & 25.7 & 24.4 \\
Factor XII & 39.0 & 17.1 & 43.91 \\
D-dimer evaluation & 38.6 & 29.8 & 31.6 \\
FDP evaluation & 49.2 & 23.8 & 27.0 \\
Protein C evaluation & 82.9 & 82.9 & 82.9 \\
Protein S evaluation & 36.4 & 16.0 & 47.7 \\
AT III evaluation & 47.2 & 20.8 & 31.9 \\
Homocysteine evaluation & 34.2 & 15.8 & 50.0 \\
\hline
\end{tabular}

$\mathrm{CT}$, computed tomography; MR, magnetic resonance; aPTT, activated partial thromboplastin time; PT, partial thromboplastin; INR, international normalized ratio; FDP, fibrinogen degradation product; AT III, antithrombin III; Angio TC, computed tomography angiography; Angio RM, magnetic resonance angiography.

Table VI. Annual and triennial mortality for DVT-PE

\begin{tabular}{llll}
\hline Mortality & DVT & PE & Total \\
\hline $\begin{array}{l}\text { Cumulative (3 years) (number } \\
\text { of cases / 100,000 inhabitants) }\end{array}$ & 1.55 & 0.65 & 2.20 \\
$\begin{array}{c}\text { Annual(number of cases / } \\
\quad 100,000 \text { inhabitants) }\end{array}$ & 0.51 & 0.21 & 0.72 \\
\hline
\end{tabular}

responders and nonresponders. Our results indicate that all characteristics of the two groups exhibit the same pattern with no statistically significant differences, so we infer that there was no selection bias in these data and that the findings may be representative of all populations of physicians.

The evidence proves that the ability to recognize all major signs and symptoms of suspected DVT-PE, although adequate, suffers from a moderate underevaluation of all the early signs and symptoms which are indicative of the problem.

- For DVT: pain (89.3\%) and edema of the lower limbs $(76.3 \%)$, fever $(24.4 \%)$, functional limitations of
Table VII. Kind of prophylaxis

\begin{tabular}{lr}
\hline Kind of device & $\%$ \\
\hline Early mobilization & 39.3 \\
Anticoagulant drugs & 93.1 \\
Elastic compression & 37.8 \\
Antiplatelet drugs & 2.2 \\
Other & 8.3 \\
\hline
\end{tabular}

Table VIII. Medical treatment before and after surgery

\begin{tabular}{lc}
\hline Kind of drug & $\%$ \\
\hline Before surgery & \\
Antibiotics & 83.9 \\
Anti-inflammatories & 14.9 \\
Anticoagulants & 80.8 \\
Antiplatelets & 15.4 \\
After surgery & \\
Antibiotics & 76.9 \\
Anti-inflammatories & 57.6 \\
Anticoagulants & 90.7 \\
Antiplatelets & 31.7 \\
\hline
\end{tabular}

Table IX. Echo color Doppler, angio-computed tomography, and D-dimer: data waiting and area

\begin{tabular}{lccc}
\hline Clinical centers & $\begin{array}{l}\text { Data waiting } \\
<12 \mathrm{hr}(\%)\end{array}$ & $\begin{array}{l}\text { Data waiting } \\
>12 \mathrm{hr}(\%)\end{array}$ & $\begin{array}{l}\text { Methodology not } \\
\text { available (\%) }\end{array}$ \\
\hline $\begin{array}{l}\text { Echo color Doppler } \\
\text { North }\end{array} \%$ & $94.16 \%$ & $5.84 \%$ \\
Center & $48.89 \%$ & $48.89 \%$ & $2.22 \%$ \\
South & $33.33 \%$ & $57.58 \%$ & $9.09 \%$ \\
Angio-computed tomography & \\
North & $7.35 \%$ & $89.71 \%$ & $35.29 \%$ \\
Center & $46.67 \%$ & $48.89 \%$ & $20.00 \%$ \\
South & $21.21 \%$ & $69.70 \%$ & $39.39 \%$ \\
D-dimer & \multicolumn{3}{l}{} \\
North & $10.29 \%$ & $80.88 \%$ & $8.82 \%$ \\
Center & $29.55 \%$ & $63.64 \%$ & $6.82 \%$ \\
South & $6.06 \%$ & $69.70 \%$ & $24.24 \%$ \\
\hline
\end{tabular}

the lower limbs (20.6\%), positive Homans maneuvre $(19.8 \%)$, venous reticula $(14.5 \%)$.

- For PE: dyspnea $(92.5 \%)$, thoracic pain $(70.1 \%)$, tachypnea $(50.7 \%)$, cough $(27.6 \%)$, hemoptysis $(26.8 \%)$, anxiety $(19.4 \%)$, sweating $(19.4 \%)$. Data suggest good clinical attention to evidence that appears more suggestive and, probably, poor attention to the complex patophysiology of the event.

Actually, guidelines are mainly aimed at physicians who do not specialize in this specific area. Indeed, they seem to be more interested in the legal 
Table X. Comparison of echo color Doppler, angio-computed tomography, and D-dimer: data waiting and mortality rate

\begin{tabular}{|c|c|c|c|c|}
\hline \multirow[b]{2}{*}{ Mortality } & \multicolumn{2}{|c|}{ Data waiting $<12 \mathrm{hr}$} & \multicolumn{2}{|c|}{ Data waiting $>12 \mathrm{hr}$} \\
\hline & DVT & $\mathrm{PE}$ & DVT & $\mathrm{PE}$ \\
\hline \multicolumn{5}{|l|}{ Echo color Doppler } \\
\hline $\begin{array}{l}\text { Cumulative ( } 3 \text { years) (number of cases } / 100,000 \\
\text { inhabitants) }\end{array}$ & 0.0052 & 0.0008 & 0.0013 & 0.1848 \\
\hline Annual(number of cases $/ 100,000$ inhabitants) & 0.0018 & 0.0000 & 0.0004 & 0.0615 \\
\hline \multicolumn{5}{|l|}{ Angio-computed tomography } \\
\hline $\begin{array}{l}\text { Cumulative ( } 3 \text { years)(number of cases } / 100,000 \\
\text { inhabitants) }\end{array}$ & 0.0114 & 0.0012 & 0.0015 & 0.1445 \\
\hline Annual (number of cases $/ 100,000$ inhabitants) & 0.0038 & 0.0004 & 0.0005 & 0.0482 \\
\hline \multicolumn{5}{|l|}{ D-dimer } \\
\hline $\begin{array}{l}\text { Cumulative ( } 3 \text { years) (number of cases / } 100.000 \\
\text { inhabitants) }\end{array}$ & 0.0049 & 0.0007 & 0.0018 & 0.1654 \\
\hline Annual (number of cases / 100.000 inhabitants) & 0.0017 & 0.0002 & 0.0006 & 0.0551 \\
\hline
\end{tabular}

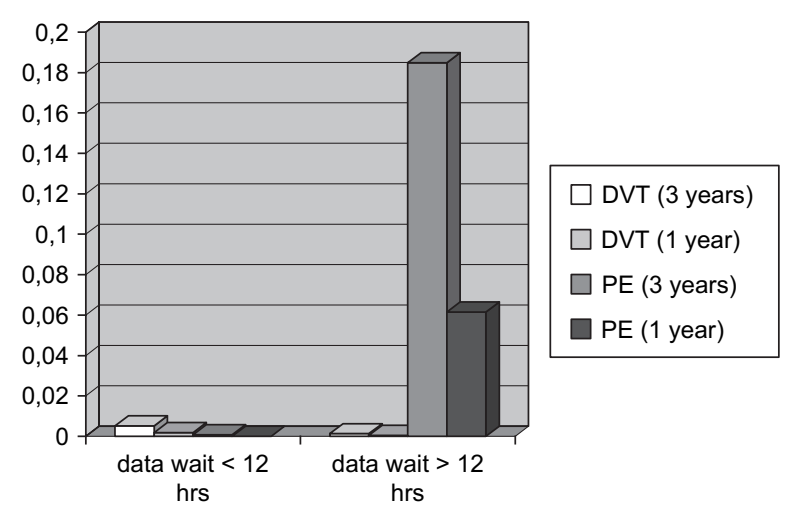

Fig. 2. Comparison of echo color Doppler data waiting and mortality rate.

aspect of a TE diagnosis, as well as instrumental and laboratory strategies, rather than following the recommendations.

The answers have demonstrated adequate knowledge of the instrumental and laboratory diagnostic pathways, useful to confirm TE $(80 \%)$. The evidence of a major interest in a main and more updated methodology (ultrasound, D-dimer, angiocomputed tomography) suggests consistent attention to the recent literature. Health-care facilities involved in this study refer to an inadequate presence of instrumental and laboratory resources, necessary to confirm risk factors for diagnosis in case of suspected disease $(80 \%)$. The element related to data waiting represented an unexpected surprise: in the vast majority of cases, data are not supplied within $12 \mathrm{hr}$. Basically, TE is a disease which can be treated thanks to adequate therapeutic systems. DVT-PE therapy is structured on the use of heparin together with a physical treatment. Pathophysiology of the

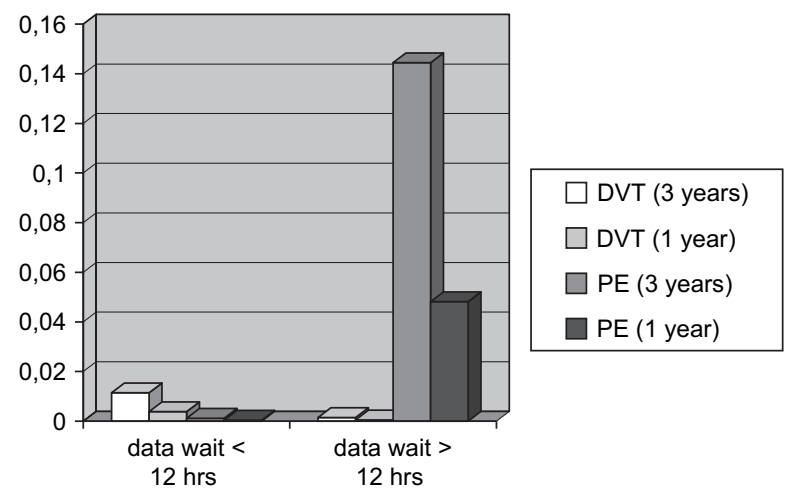

Fig. 3. Comparison of angio-computed tomography data waiting and mortality rate.

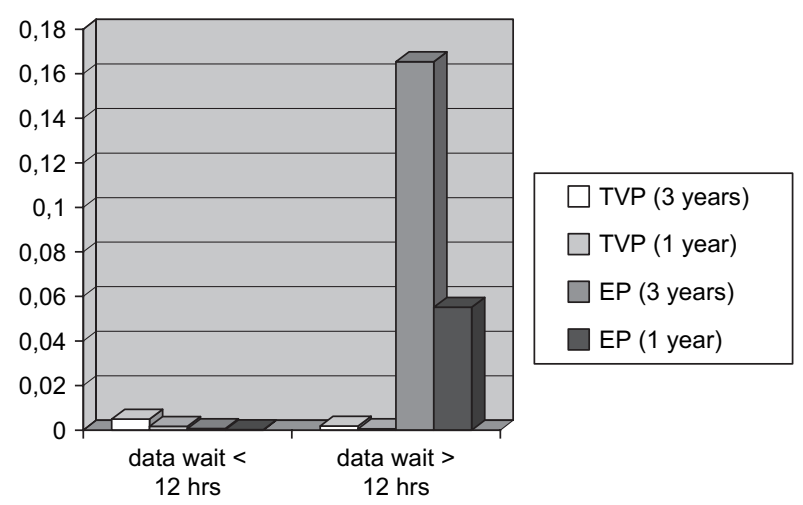

Fig. 4. Comparison of D-dimer data waiting and mortality rate.

thromboembolic disease suggests that a precocious therapeutic action represents the limit between the solution of the episode and the evolution to complications. A diagnostic delay can severely 
Table XI. Morbidity and mortality rates versus clinical centers

\begin{tabular}{|c|c|c|c|c|}
\hline & \multicolumn{2}{|c|}{ Cumulative ( 3 years) (number of cases/100,000 inhabitants) } & \multicolumn{2}{|c|}{ Annual (number of cases/100,000 inhabitants) } \\
\hline & DVT & $\mathrm{PE}$ & DVT & $\mathrm{PE}$ \\
\hline \multicolumn{5}{|l|}{ Morbidity } \\
\hline General Surgery & 0.0280 & 0.02427 & 0.0093 & 0.0810 \\
\hline Orthopedics & 0.2057 & 0.1845 & 0.0686 & 0.0615 \\
\hline Gynecology & 0.0589 & 0.0536 & 0.0196 & 0.0179 \\
\hline \multicolumn{5}{|l|}{ Mortality } \\
\hline General Surgery & 0.0034 & 0.7828 & 0.0011 & 0.2609 \\
\hline Orthopedics & 0.0020 & 0.0017 & 0.0001 & 0.0001 \\
\hline Gynecology & 0.0015 & 0.0003 & 0.0005 & 0.00001 \\
\hline
\end{tabular}

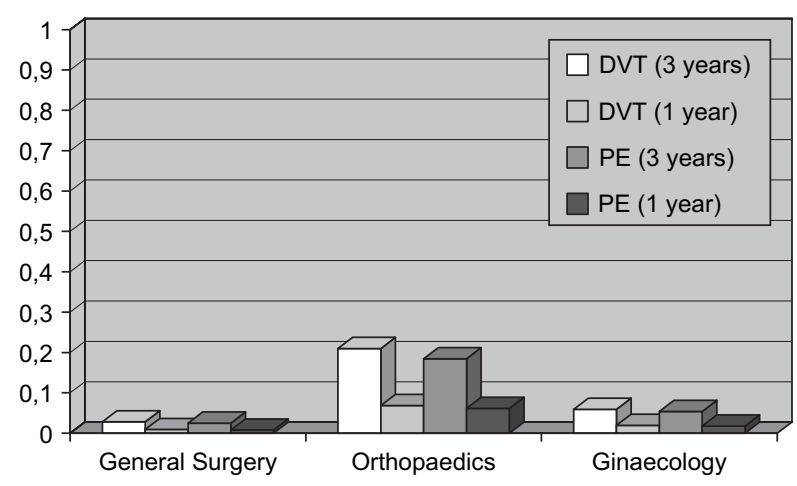

Fig. 5. Morbidity rate versus clinical centers.

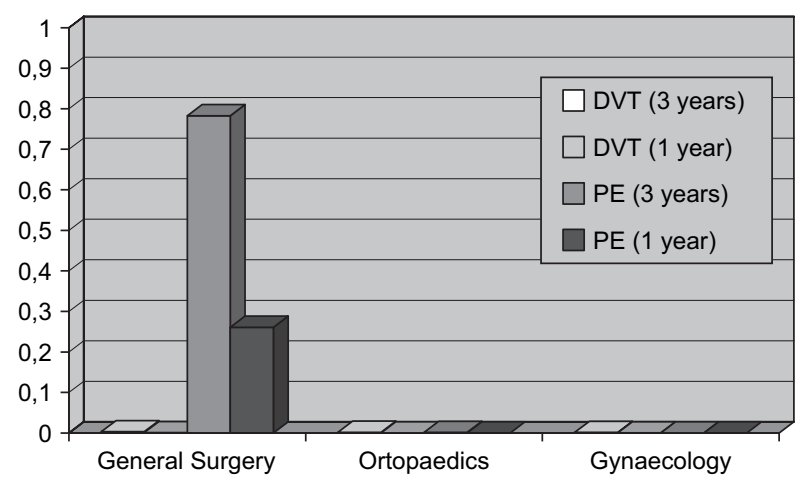

Fig. 6. Mortality data versus clinical centers.

influence the efficacy of therapy. What can be supposed is that when a diagnostic pathway is defined, it is necessary to think of an "effective diagnosis," i.e., a useful diagnosis, in the answer and timing in order to apply the correct therapy. Guidelines, although precise, accurate, and schematic in diagnostic recommendations, never mention adequate timing for the diagnostic procedures. To confirm the above-mentioned, data waiting and mortality in DVT-PE were elaborated and compared. It is evident that an absolute increase of mortality related to a delay (of more than $12 \mathrm{hr}$ ) in the supplying of data. This delay was the same for DVT and PE but probably more important for DVT because this led to PE not being diagnosed and, consequently, to an apparent increase of mortality for DVT. In this group of answers concerning mortality, a low mortality rate in DVT was reported. The centers were asked about mortality data only for patients with confirmed or post-mortem diagnosis; thus, the declared mortality in PE by all means refers to events intrinsically mortal.

Mortality in DVT may represent an underestimated element related to the lack of diagnosis of PE or to a major event different from PE that arose before its identification. The literature indicates a known mortality from PE of 13\% (8.97/100,000 inhabitants), ${ }^{10}$ so the data for mortality from DVT, which might represent a risk factor for TE, should be investigated. In recent years, different incidence rates of morbidity and mortality for TE related to the kind of patient, i.e., those attending general surgery, gynecology, and orthopedics units, have emerged in various studies. ${ }^{5,6}$ Differences seem to be related to a different sensitivity to the problem and to varying cultural integration of single specialities.

In this study, a higher mortality from PE was found in general surgery departments and a higher morbidity for DVT and PE in orthopedics and gynecology. It can be supposed that higher morbidity coincides with a best identification that coincides with an adequate treatment and vice versa. The identified anomalies related to data waiting and mortality were investigated, creating from the whole data a partial regional data area (north, center, south). The most inadequate answers seem to belong to the northern regions that traditionally are recognized as being equipped with high technology and structural resources. An explanation could be attributed to the different health-care regional systems, expressed by different applications of the DiagnosisRelated Groups system that might represent, in 
this case, a health-care disadvantage or deficiency. VTE is a major cause of mortality and morbidity for Western populations. Its annual incidence over the general population is $145 / 100,000$ for DVT and $69 / 100,000$ for PE. ${ }^{1-13}$ Just $13 \%$ of PE cases are fatal (mortality 8.97 cases/100,000 inhabitants ${ }^{1}$ ). Thus, VTE is a major issue in health care and social cost. ${ }^{14-16}$ About three-fourths of VTE cases occur in medical patients, and about one-fourth are found in surgical patients for whom risk factors represent a precise condition.

\section{CONCLUSIONS}

Surgical procedure and trauma involve a higher probability of developing a major event. In these patients, risk stratification and adequate application of prophylaxis and treatment devices represent a real possibility to control morbidity and mortality. Diagnostic data waiting is a fundamental factor for adequate prophylaxis, and this study has clearly shown that in Italy only $40 \%$ of centers today are able to provide diagnostic data within $12 \mathrm{hr}$.

\begin{tabular}{|c|c|c|}
\hline Hospital & Department & Head \\
\hline Casa di cura S. Rita Ciro' Marina-Kr & General Surgery & E. Massari \\
\hline Ospedale di Palermo & General Surgery & G. Lombardo \\
\hline Ospedale di Latina-Formia & General Surgery & G. Cardi \\
\hline Ospedale di Matera & Orthopedics & A. Laforgia \\
\hline Ospedale di Ragusa & Gynecology and Obstetrics & S. Iannizzotto \\
\hline Ospedale di Caltanissetta & Orthopedics & D. Morgante \\
\hline ASL n7 Ospedale diRagusa & Gynecology and Obstetrics & S. D'Asta \\
\hline Ospedale di Roma & General Surgery & M. Farao \\
\hline Osp. S. Francesco Venosa Potenza & Orthopedics & G. Bruno \\
\hline Asl n6 Ospedale di Cefalu'- Palermo & General Surgery & G. Mastrandrea \\
\hline Ospedale di Rossano & General Surgery & L. Cloro \\
\hline Casa di cura Sant'Anna Cagliari & Gynecology and Obstetrics & F. Angioni \\
\hline Ospedale Cristo Re Roma & General Surgery & C. Allegri \\
\hline Ospedale Santa Maria della Misericordia Sorrento & General Surgery & De Rosa \\
\hline Ospedale Monadi di Napoli & Orthopedics & R. Magri \\
\hline Ospedale di Salerno & Orthopedics & S. D'Auria \\
\hline Ospedale di Cosenza & General Surgery & A. Petrassi \\
\hline Ospedale di Potenza & Orthopedics & S. Accordo \\
\hline Ospedale di Trapani & Gynecology and Obstetrics & A. Governale \\
\hline Villa del Sole Catanzaro & General Surgery & V. Aloi \\
\hline Ospedale di Catania & Gynecology and Obstetrics & S. Caschetto \\
\hline Ospedale di Castrovillari & Orthopedics & L. Tarsia \\
\hline Casa di cura S. Giuseppe, Roma & Orthopedics & A. Schiavone Panni \\
\hline Ospedale di Roma & General Surgery & E. Fedele \\
\hline Ospedale di SCIACCA & Orthopedics & A. Vella \\
\hline Ospedale di Potenza & General Surgery & L. Luccioni \\
\hline Ospedale di Napoli & Orthopedics & L. Grosso \\
\hline Ospedale di Isernia & Gynecology and Obstetrics & L. Falasca \\
\hline Ospedale Civile di Atessa & General Surgery & A. M. Vitalone \\
\hline Ospedale di Lanciano, Vasto & General Surgery & G. Marchese \\
\hline Ospedale Renzetti, Lanciano & General Surgery & G. Lesti \\
\hline Ospedale San Liberatore, Teramo & Orthopedics & T. De Iure \\
\hline Ospedale San Salvatore, L'Aquila & Gynecology and Obstetrics & F. Cappa \\
\hline Azienda Ospedaliera Senese & General Surgery & S. Mancini \\
\hline Ospedale di Piombino (ASL 6), Livorno & General Surgery & A. Andreini \\
\hline Azienda Ospedaliera Careggi, Firenze & Orthopedics & R. Capanna \\
\hline Azienda Ospedaliera Senese & Orthopedics & L. Bocchi \\
\hline Ospedale di Fivizzano (ASL 1), Massa & Orthopedics & S. Limontini \\
\hline Ospedale di Massa (ASL 1) Massa & Gynecology and obstretics & D. Milano \\
\hline Ospedale di Piombino (ASL 6) Livorno & Gynecology and Obstretics & N. Calonaci \\
\hline Ospedale di Empoli (ASL 11) & Gynecology and Obstetrics & M. Filippeschi \\
\hline Azienda Ospedaliera Senese & Gynecology and Obstetrics & F. Petraglia \\
\hline
\end{tabular}


This study has benefited from a grant provided by the Italian Ministry of Research to the project National Epidemiologic Survey on Postoperative Morbidity of Deep Vein Thrombosis (DVT) and Pulmonary Embolism (PE). Screening of Patients at Risk and Clinical-Statistical Evaluation of Prophylaxis and Treatment Methods. Validation of Results. Proposal for a National Protocol. Special thanks to those listed in the table and to all physicians who contributed to this study and whose name it was not possible to include. We thank Sony Ericsson for having provided communication tools to local units.

\section{REFERENCES}

1. Geerts WH, Pineo GF, Heit JA, et al. Prevention of venous thromboembolism: the Seventh ACCP Conference on Antithrombotic and Thrombolytic Therapy. Chest 2004;126: 338S-400S.

2. Lindblad B, Sternby N, Bergqvist D. Incidence of venous thromboembolism verifyed by necroscopy over 30 years. BMJ 1991;302:709-711.

3. Di Minno G, Tufano A. Challenges in the prevention of venous thromboembolism in the elderly. J Thromb Haemost 2004;2:1292-1298.

4. Wells PS, Anderson DR, Bormanis J, et al. Value of assessment of pretest probability of deep-vein thrombosis in clinical management. Lancet 1997;350:1795.

5. Collins R, Scrimgeour A, Yusuf S, et al. Reduction in fatal pulmonary embolism and venous thrombosis by perioperative administration of subcutaneous heparin. Overview of results of randomized trials in general, orthopedic, and urologic surgery. N Engl J Med 1988;318:1162-1173.
6. Geerts WH, Code KI, Jay RM, et al. A prospective study of venous thromboembolism after major trauma. N Engl J Med 1994;331:1601-1606.

7. Cummings SM, Savitz LA, Konrad TR. Reported response rates to mailed physician questionnaires. Health Serv Res 2001;35:1347-1355.

8. Kellerman SE, Herold J. Physician response to surveys. A review of the literature. Am J Prev Med 2001;20:61-67.

9. Abramson JH. Survey Methods in Community Medicine: Epidemiological Studies, Programme Evaluation, Clinical Trials. 4th ed. London: Churchill Livingstone, 1990.

10. Browse NL, Burnand KG, Thomas ML. Pathology, diagnosis and treatment. In: Diseases of the Veins. London: Edward Arnold, 1988. pp 233-237.

11. Gillum RF. Pulmonary embolism and thrombophlebitis in the United States, 1970-1985. Am Heart J 1987;1 14:1262.

12. Anderson FA, Jr, Wheeler HB, Goldberg RJ, et al. A population-based perspective of the hospital incidence and case-fatality rates of deep vein thrombosis and pulmonary embolism. The Worcester DVT Study. Arch Intern Med 1991;151:933.

13. Silverstein MD, Heit JA, Mohr DN, et al. Trends in the incidence of deep vein thrombosis and pulmonary embolism: a 25-year population-based study. Arch Intern Med 1998; 158:585.

14. Bick RL. Therapy for venous thrombosis: guidelines for a competent and cost-effective approach. Clin Appl Thromb Hemost 1999;5:2-9.

15. Medicare \& DRG, http://www.hcfa.gov; 1996.

16. Bergqvist D, Jendteg S, Johansen L, et al. Cost of long-term complications of deep venous thrombosis of the lower extremities: an analysis of a defined patient population in Sweden. Ann Intern Med 1997;126: 454-457. 